\title{
Some Comments on Big Data and Data Science
}

\author{
Jifa Gu • Lingling Zhang
}

Received: 1 October 2014 / Revised: 1 November 2014 / Accepted: 20 December 2014 /

Published online: 11 January 2015

(C) Springer-Verlag Berlin Heidelberg 2015

\begin{abstract}
Based on previous paper titled in "Data, DIKW, Big data and Data science" presented in ITQM2014 and published in Procedia Computer Science we will make some modifications. We discuss the relationship between data and data-informationknowledge-wisdom. Now the big data occupies much attention in some extent for his volume, velocity, and variety. But in practical use the value plays more important role. Finally to judge the value for data not necessary for big, in some cases the small data also may lead to big value. So we appreciate the data science, which may consider more inherent value from data. We will make some comments on the big data and data science from another angle.
\end{abstract}

Keywords Data $\cdot$ DIKW $\cdot$ Big data $\cdot$ Small data $\cdot$ Data science $\cdot$ Comments

\section{Data and Hierarchy of DIKW}

The hierarchy of DIKW is data, information, knowledge, wisdom: a four layer hierarchy, where each layer adds certain attributes over and above the previous one (see Fig. 1). Data is the most basic level; information adds context; knowledge adds how to use it; wisdom adds when and why to use it [1,2]. A further elaboration of Ackoff's definitions follows: data is raw. It can exist in any form, usable or not. It does not have meaning of itself. Information is data that has been given meaning by way of rela-

\footnotetext{
J. Gu (凶)

Academy of Mathematics and Systems Science, Chinese Academy of Sciences, 55 Zhongguancun East Road, Beijing 100190, China

e-mail: jfgu@amss.ac.cn

L. Zhang

School of Management, University of Chinese Academy of Sciences, Beijing 100190, China
} 
Fig. 1 D-I-K-W hierarchy
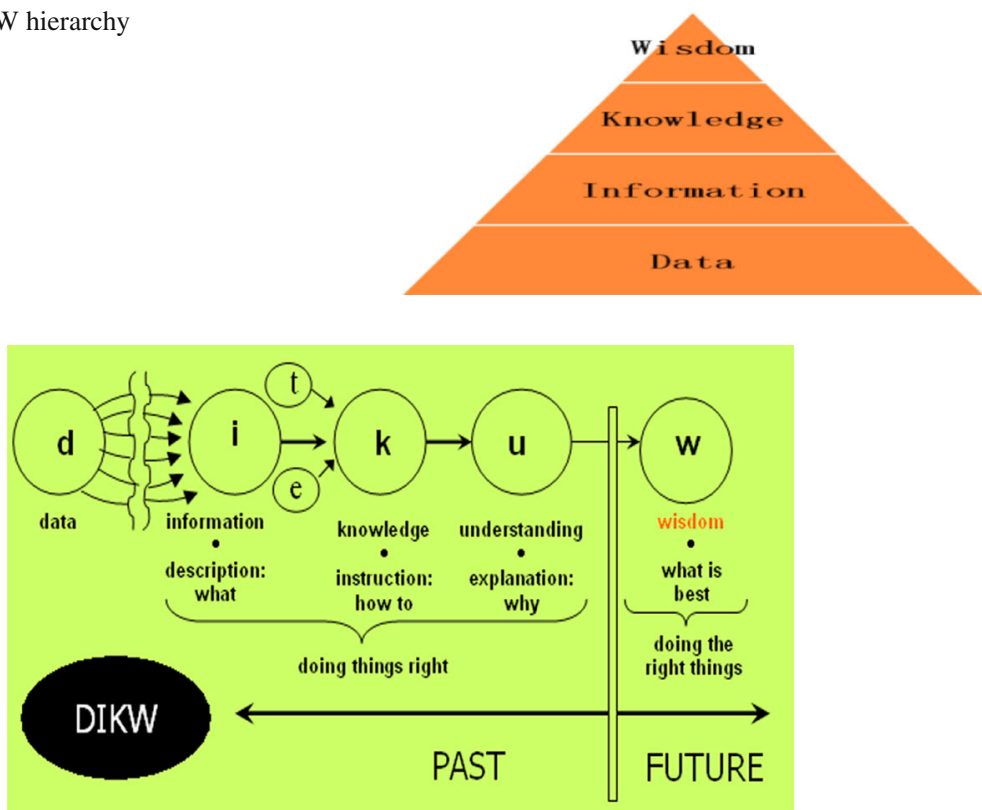

Fig. 2 A flow diagram of the DIKW hierarchy [2]

tional connection. This "meaning" can be useful, but does not have to be. Knowledge is the appropriate collection of information, such that its intent is to be useful. This knowledge has useful meaning to them, but it does not provide for, in and of itself, integration such as would infer further knowledge. Between knowledge and wisdom Ackoff add understanding. Understanding is cognitive and analytical. It is the process by which people can take knowledge and synthesize new knowledge from the previously held knowledge. Wisdom calls upon all the previous levels of consciousness, and specifically upon special types of human programming (moral, ethical codes, etc.) (see Fig. 2) [3,4]. In the meaning of hierarchy of DIKW the data just a basic fact and raw that will be useful only let them evolve to the information, knowledge and wisdom. In the previous two levels of data and information we may use a lot of methods such as data mining, text mining, web mining and tools such as data base, data warehouse and management information system to let them to be useful. In order to move forward to the third level of knowledge we should use KDD, knowledge engineering and management, intelligent knowledge [5]. Given large-scale databases, intelligent knowledge management enables to generate "special" knowledge, called intelligent knowledge base on the hidden patterns created by data mining. The process of intelligent knowledge management - a new proposition from original data, rough knowledge, intelligent knowledge, and actionable knowledge is proposed [6]. Especially in considering the expert experiences to let the knowledge extracted by some methods like data mining to be more useful, we use so-called domain driven data mining $[7,8]$. For the sake of fully utilizing the expert experience we propose expert mining, by which people may use properly the data, information and knowledge [9-11]. 


\section{Big Data}

\subsection{A Short History of Big Data}

The story of how data became big starts many years before the current tide around big data. Already 70 years ago we encounter the first attempts to quantify the growth rate in the volume of data or what has popularly been known as the "information explosion". There are several phases in the history of sizing data volumes plus other "firsts" in the evolution of the idea of "big data"; we adopt most information from G. Press [12] and with minor modifications [1]. But here we will omit the detail history.

Authors find that for the volume of big data, its magnitude are from PB (19442000), EB (2002-2007), even ZB (2009), and for the specific features now in big data there appeared $4 \mathrm{~V}$, the first three Volume, Velocity, and Variety are the same in 2001, but the last V some says it is Veracity, most mentions Value, probably they will add some more features. Authors especially emphasize the value transformed from data.

\subsection{Some Comments on Big Data}

With the rapid development in studying and using the term of big data we just want put forward some comments.

\subsubsection{Big Data Comment 1: Complexity}

We should pay much attention on the complexity of the structures and contents behind big data, as Qian et al. mentioned in 1990 we had confronted difficult problems happened in so called open complex giant (OCG) systems, which originated in social system, economical system, geographical system and human body system (around 10 years later Qian's colleagues Dai pointed out that the internet is also an open giant complex systems). The feature of "giant" just corresponded to the big data because of large number of elements, data and information in OCG systems, but the feature of "complex" in some extent wasn't too much been emphasized in the professionals in the fields of technical cycle, they pay too much attention to the technical treatment on big data by using advanced computer and information technology [13].

\subsubsection{Big Data Comment 2: From Small to Big, then from Big to Small}

According to Li's opinion in 2012 we had made the small data to the big data in recent years, but now we should transfer the big data to small data discarding the dross and select the essential [14]. There are same thoughts related to big information even in twentieth century, some authors afraid that too much information is not good thing. Qian had mentioned similar views even in 1992, that now during the time of information revolution, the quantity of information like the sea will be surging over us, as a human in twenty first century you must be not drown. It means you must have a high intellectual level to manage it, otherwise you will be drowning [15]. As a matter of fact we had suffered the information overload even in the beginning of 
twenty first century $[16,17]$, in paper [16] Shi had proposed theory of human casting to reduce information overload. Thus can we propose the similar methods for reducing the volume of data.

As a matter of fact in the cycle of statisticians often use the sampling method to describe the features existed in the large population, so once a time one of my colleagues in the field of statistics just suspects on correctness for the census survey in all population, it means although we wish obtain entire data set (it certainly is big data), but with limitation of the time, effort and budget, especially because of error data existed by carelessness from some census teams. It may possibly if we organize some small census teams with good training which may obtain the similar estimation from the complete census. Certainly it ask us to have a scientific design of sampling.

\subsubsection{Big Data Comment 3: Data Must Evolve to Correct Knowledge}

In the first paragraph we had mentioned that as the data it should evolve into D-I-K$\mathrm{W}$, without transforming the data to knowledge, especially useful knowledge, it just nothing to do. Like a people have a lot of bricks, cement, wood and steel if you don't have help from a good designer you couldn't transfer them into a real construction. Then we also mention between the knowledge and wisdom there exist understanding. It is the process by which people can take knowledge and synthesize new knowledge from the previously held knowledge. So also if you have big data, you should also try to let other people to understand, to utilize it, this is also the view by Kong, chief manager from Teradata [18].

\subsubsection{Big Data Comment 4: Tacit Knowledge}

From the point of views of knowledge science the data usually belongs to explicit knowledge, but sometime we even pay much attention to the tacit knowledge. For that purpose Nonaka proposed so called SECI model in helping people to transfer the tacit knowledge into explicit knowledge. Then as compared with the individual knowledge we should pay attention the organizational knowledge and collective knowledge, it means sometime the same data in front of different individual there appear different understanding, but after discussion, exchange and analysis a group of experts will generate more correct and useful knowledge [19]. Even more Nonaka emphasizes the practical wisdom (phronesis), that we must pay attention the morality, it means the knowledge will be useful is closely related to the goodness for the most people [20]. It just point out the Value, the forth $\mathrm{V}$ for big data.

\subsubsection{Big Data Comment 5: Data Value}

About the value of big data we wish illustrate two examples related to such kind of problems: how can we use the big data. The first example is related to the project of Analysis, Dissemination, Visualization, Insight and Semantic Enhancement (ADVISE) system, the ADVISE system run by DHS of USA and supported by a large group of experts and researchers in order to collect and analyze enough big data starting from 2004, they use various channels for collecting the data and information from the internet, 
telephone, border custom and sensors from various detecting equipment etc., which will be useful to detecting the terrorists information. We especially appreciate them by using the complex network and semantic analysis (sometimes they also used the data mining instead) and try to let these big data useful to identify the terrorists. But with the rapid growth of number of data and information collected from terrorists and other common people who are not the terrorists by this system, because of the reason of violating privacy of common people the US congress finally prohibited this system to work anymore in the August of 2007. But as a matter of fact that was just a surface phenomenon for US government, they had to force to stop ADVISE, but has found the another similar projects to collect even more wide and deep information, such as PRISM starting in 2009 exhibited by Snowden. To this event US government assumes that Snowden is a traitor, but some other countries assume that he is a hero. So the same data handled by different people will have different value. For more discussion on big data problem you may find author's paper [21].

\section{Data Science}

The term "data science" has emerged only recently to specifically designate a new profession that is expected to make sense of the vast stores of big data. But making sense of data has a long history.

\subsection{A Short History of Data Science}

G. Press has made a good and comprehensive description about the short story of data science; here author just wishes mention the similar terms of data science, such as data analysis, datalogy and data scientist etc., and we just list some of them [22].

1974 Naur says "Datalogy, the science of data and of data processes and its place in education, "and "the term 'data science' has been used freely." He offers the following definition of data science: "The science of dealing with data, once they have been established, while the relation of the data to what they represent is delegated to other fields and sciences".

2001 Cleveland publishes "Data Science: An Action Plan for Expanding the Technical Areas of the Field of Statistics." It is a plan "to enlarge the major areas of technical work of the field of statistics. Because the plan is ambitious and implies substantial change, the altered field will be called 'data science.",

2010 Loukides writes in "What is Data Science?" They are inherently interdisciplinary. They can tackle all aspects of a problem, from initial data collection and data conditioning to drawing conclusions. They can think outside the box to come up with new ways to view the problem, or to work with very broadly defined problems: 'here's a lot of data, what can you make from it?"'

2010 Mason and Wiggins write in "A Taxonomy of Data Science”: “... what a data scientist does, in roughly chronological order: Obtain, Scrub, Explore, Model, and iNterpret...Data science is clearly a blend of the hackers' arts... statistics and machine learning... and the expertise in mathematics and the domain of the data for 
the analysis to be interpretable... It requires creative decisions and open-mindedness in a scientific context."

2011 Warden writes in "Why the term 'data science' is flawed but useful": "There is no widely accepted boundary for what's inside and outside of data science's scope, people tend to work beyond the narrow specialties that dominate the corporate and institutional world, handling everything from finding the data, processing it at scale, visualizing it and writing it up as a story. They also seem to start by looking at what the data can tell them, and then picking interesting threads to follow, rather than the traditional scientist's approach of choosing the problem first and then finding data to shed light on it."

2011 Smith writes in “'Data Science': What's in a name?” I think 'Data Science' better describes what we actually do: a combination of computer hacking, data analysis, and problem solving."

2011 Harris writes in "Data Science, Moore's Law, and Money ball”: “'Data Science' is defined as what 'Data Scientists' does. What Data Scientists do has been very well covered, and it runs the gamut from data collection and mugging, through application of statistics and machine learning and related techniques, to interpretation, communication, and visualization of the results."

2012 Davenport and Patil publish "Data Scientist: The Sexiest Job of the 21st Century" in the Harvard Business Review. [22].

Authors wish add two other sources about data science:

2005 Joint report by Sandia National Laboratory and Lawrence Livermore: "Data sciences information technology for homeland security information management and knowledge discovery" [23]. This report was the first paper to mention author to use the term of data science.

2009 Zhu and Xiong, publish "Introduction to Dataology and Data Science," in which they state "Different from natural science and social science, Dataology and Data Science takes data in cyberspace as its research object. It is a new science" [24].

\subsection{Some Comments on Data Science}

In China there is a series of science conference named Xiangshan science conference, which is the general designation of a small-scale academic workshop series, is supported by some very important organizations related to the science and technology, such as Ministry of Science and Technology, Chinese Academy of Sciences, NSFC, and Ministry of Education, etc. The topics selected by scientists according to its interdisciplinary cooperation and integrated studies in various areas of excellence and exploring new frontiers. And in the 278 session contributed to "Data technology and knowledge economy" (May 22-24, 2006), Gu had attended this session and expressed two opinions based on his own practices: (1) from data mining to expert mining and (2) from data technology to data science. In May of 2013 there is another Xiangshan science conference, 462 session, titled in "Data science and big data" chaired by Shi from the research center on Fictitious Economy and Data Science, Chinese Academy of Sciences and Zhu from Research Center for Dataology and Data Science and other two professors $\mathrm{Yu}$ and Li. In that conference Chinese scholars just wish to perfect the 
definition, contents, methods and applications for Data science. After this conference many speakers have published series of papers in the Journal of Science and Technology for Development in the beginning of 2014, Gu also publish his paper in this journal related to the issues on big data [21].

Based on these two opinions we wish make three comments.

\subsubsection{Data Science Comment 1: ADVISE Project}

From 2005 J.F. Gu had engaged in one project related to the social system problem, in this project we have to deal with the huge amount of data and information, so at first ADVISE project closely linked to data mining. In 2006 we read the document on "Data sciences, information technology for homeland security information management and knowledge discovery" written by Sandia National Laboratory and Lawrence Livermore in January of 2005. Gu appreciate the terminology of data science very much. It means that ADVISE didn't want stop in the data mining, instead of using the data science, they pay much attention also to the knowledge management. In that time Gu had applied the Meta-synthesis system approach to solve the social problem. This approach not only pays attention to utilize the data, information, but also the experiences and wisdom from experts and decision makers. So Gu had published the paper related to so call expert mining, which pays attention on expert experience, judgment, understanding and making decision $[9,11]$.

\subsubsection{Data Science Comment 2: Expert Mining}

Another project related to the traditional Chinese medicine (TCM), we wish inherit the experiences and idea from some veteran and famous TCM doctors in China. In this project we may use the number of data and information, just a few, from statistics point that is a small sample problem. Again we use the expert mining to solve the problem [10]. Here really we just wish mention that we met not with a big data problem, but a small data. But we think the data science will resolve also this problem, if we set the data science, including both big data and small data, only we should use new theory, different advanced methods and techniques. We should introduce the intelligent knowledge management $[5,6]$, domain driven data mining $[7,8]$ and expert mining [25] etc.

\subsubsection{Data Science Comment 3: Artificial Data}

The data not necessary comes from real world, now with the development of computer technology we may create a lot of artificial data from computer. Now the numerical simulation may generate enough data as we required. Especially when we deal with the social problems, since it is hard to collect the real data, sometime it involves the privacy of common people, sometime we have to pay a lot of money to buy some real useful data and information, so we often have to use the cheap data generated from computer. 


\section{Conclusion}

Authors just wish explain some relationships within the data, D-I-K-W, big data and data science. On the one hand we want emphasize the utilization of data that must evolve to knowledge and wisdom, on the other hand we wish to point out that too much emphasizing the data "big", sometime may not solve all problems. In some problems we really have only possibility to collect just a few data and information. So we wish to develop the data science as soon as quickly to cover and solve much more issues which we had met already. Certainly to establish an entire theory for data science requires all of us to make more effort and deep consideration.

Acknowledgments We wish to acknowledge Shi Y. and his colleagues from the research center on Fictitious Economy and Data Science, Chinese Academy of Sciences for their kind support, freely exchange and discussion of views on data mining, expert mining, big data and data science. This paper was also supported by NSFC (National Natural Science Foundation of China, No. 71071151 and No. 71471169) and 973 plan (2010CB731400).

\section{References}

1. Gu JF, Zhang LL (2014) Data, DIKW, big data and data science. Procedia Comput Sci 31:814-821. 2nd international conference on information technology and quantitative management (ITQM2014). Moscow, Russia

2. Wikipedia (2011) DIKW pyramid, http://en.wikipedia.org/wiki/DIKW. Accessed 15 Dec 2011

3. Gu J (2013) Data, information, knowledge, wisdom and meta-synthesis of wisdom-comment on wisdom global and wisdom cities, Procedia Computer Science, Volume 17. First international conference on information technology and quantitative management (ITQM2013), Beijing, China, pp 713-719

4. Bellinger G, Castro D, Mills A (2004) Data, information, knowledge and wisdom, http://www. Systems-thinking.org/dikw/dikw.htm

5. Leondes CT (2010) Intelligent knowledge-based systems: business and technology in the new millennium. Springer

6. Zhang LL, Li J, Li AH, Zhang P, Nie GL, Shi Y (2009) A new research field: intelligent knowledge management, International conference on business intelligence and financial engineering, 2009 (BIFE '09), Beijing, 24-26 July 2009, pp 450-454

7. Cao LB, Zhang CQ (2006) Domain-driven actionable knowledge discovery in the real world, PAKDD 2006. LNAI 3918:821-830

8. Zhu ZX (2008) Toward domain-driven data mining, International symposium on intelligent information technology application workshops, 2008, IITAW '08. 21-22 Shanghai, pp 44-48

9. Gu JF (2006) Expert mining for discussing the social complex problems, MCS2006, Beijing

10. Gu JF, Song WQ, Zhu ZX, Gao R, Liu YJ (2008) Expert mining and TCM knowledge, KSS2008, Guangzhou, December 11-13

11. Gu JF, Liu YJ, Zhu ZX (2014) Expert mining and meta-synthesis. Science Press, Beijing (in Chinese)

12. Gil Press (2012) A very short history of big data, http://whatsthebigdata.com/2012/06/06/a-very-shorthistory-of-big-data/. Accessed 6 Jun 2012

13. Qian XS, Yu JY, Dai RW (1990) A new scientific discipline-open complex giant systems and its methodology. J Nat 13(1):3-10 (in Chinese)

14. Gan X, Academician Li GJ (2012) Big data turns into new interesting points in IT, China Science Daily, 27 Jun 2012

15. Qian XS (2011) 21 century is the century for the competition of information, we should grasp now the construction of information network. In: Jiang L (ed) Qian X.S., on Systems science (collections of talks). Science Press, Beijing, pp 101-107

16. Shi Y, Gu JF, Tang XJ (2000) Information overload. In: Zeleny M (ed) The IEBM handbook of information technology in business. Business Press, Thomson learning, London 
17. Shi Y (2013) Three important technical issues on big data, IT Expert net, 25 Aug 2013, http://m.ctocio. com.cn/storage/359/12698859_m.shtml (in Chinese)

18. Huo N (2013) Teradata: big data should go to easily to use and to be popular. Zhongguojisuanjibao 17:24. http://www.zcom.com/article/107572/

19. Nonaka I, Takeuchi H (1995) The knowledge-creating company: how Japanese companies create the dynamics of innovation. Oxford University Press, New York

20. Nonaka I, Toyama R, Hirata T et al (2008) Managing flow: a process theory of the knowledge-based firm. Palgrave Macmillan, New York

21. Gu JF (2014) Some issues on big data. Sci Technol Dev 10(1):20-24 (in Chinese)

22. Gil Press (2013) A very short history of data science, http://www.forbes.com/sites/gilpress/2013/05/ 28/a-very-short-history-of-data-science/2/

23. Joint report by Sandia National Laboratory and Lawrence Livermore (2005) Data sciences, information technology for homeland security information management and knowledge discovery, Sandia report SAND2004-6648, LINL report UCRL-TR-208926, January 2005

24. Zhu YY, Xiong Y (2009) Dataology and data science. Fudan University Press, Shanghai (in Chinese)

25. Gu JF (2010) Expert mining: realization of knowledge synthesis. J Eng Stud 2(2):100-107 (in Chinese)

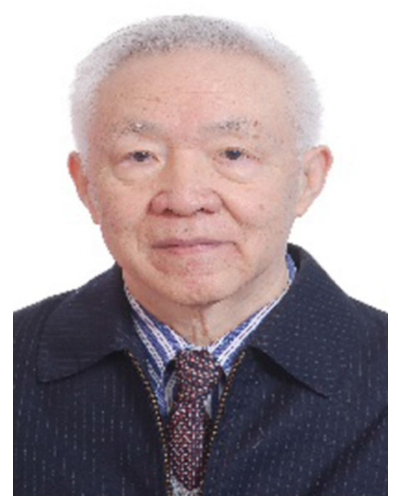

Jifa Gu Professor, Academy of Mathematics and Systems Sciences, Chinese Academy of Sciences, Bachelor, Peking University, PhD, Institute of Mathematics, USSR Academy of Sciences, working in the fields of Operations Research and Systems Engineering. He published more than 30 books and 200 journal papers. He participated in practices on missile, energy, environment, water resource, regional strategy and various projects on evaluation. 1995 with Dr. Zhu ZC proposed Wuli-Shili-Renli system approach and got applications in many practical cases. In recent 10 years he has engaged in the study and application of Meta-synthesis system approach and Knowledge Science. He has participated in several national research programs related to social issues, digging experiences from TCM veteran doctors and study on the collective behaviors in Shanghai World Expo. $\mathrm{He}$ had been President of Systems Engineering Society of China, President of International Federation of System Research. Now he is academician and vice president of International Academy of System and Cybernetics, academician of Euro-Asia Academy of Sciences.

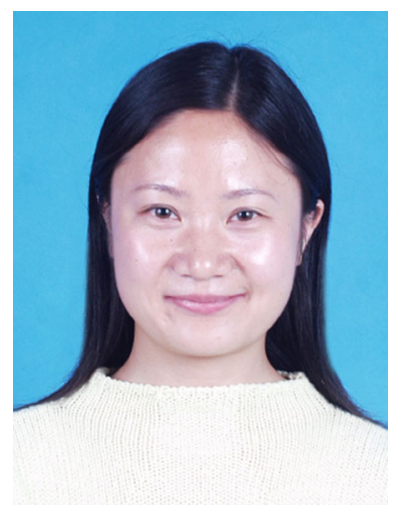

Lingling Zhang currently is Associate Professor at School of Management, University of Chinese Academy of Sciences. She also works as a researcher at Research Centre on Fictitious Economy \& Data Science, Chinese Academy of Sciences. She was once visiting scholar of Stanford University in the USA. Currently, her research interests include data mining, intelligent knowledge management, and management information system. She has received three Grant supported by the Natural Science Foundation of China (NSFC), published 4 books, more than 40 papers in various journals. 